\title{
Penicillosis in Patient of Acute Kidney Injury with Adenocarcinoma Lung: A Rare Presentation
}

\section{Upma Narain $^{1^{*}}$ and Arvind Gupta ${ }^{2}$}

${ }^{1}$ Department of Microbiology and Immunology, Tejas Microdiagnostic, Allahabad, Uttar Pradesh, India

${ }^{2}$ Department of Nephrology, Moti Lal Nehru Medical College, Allahabad, Uttar Pradesh, India

\begin{abstract}
Fungal infections are an increasing problem in immunocompromised patients. Members of the genus Penicillium rarely cause infections and are primarily limited to strains of the species Penicillium marnaffei. We are reporting a successfully treated case of culture proven pulmonary Penicillosis caused by Penicillium chrysogenum on the onset of Acute Kidney Injury in a patient of ademocarcinoma lung.
\end{abstract}

Keywords: Penicillosis; Acute kidney injury; Broncho alveolar lavage; Penicillium chrysogenum; Ademocarcinoma lung; Haemodialysis

\section{Introduction}

Penicillosis is an invasive fungal infection that primarily occurs in the south east and eastern regions of Asia [1]. Penicillium species are among the most common fungi in the environment and are usually considered non-pathogenic to humans [2]. However in immunocompromised host they can be virulent pathogen and can cause death [3]. Acute kidney injury (AKI) is common in cancers [4] and patients on cytotoxic drugs are susceptible to opportunistic infections. Significant proportion of cancer patients are affected by pulmonary infections. Successful outcome requires early identification, aggressive and effective treatment of the infection. Herein, we report the case of successful treatment of concomitant pulmonary Penicillosis and acute kidney injury in the patient of adenocarcinoma lung.

\section{Case Report}

He was the diagnosed case of diabetes mellitus, hypertension, hypothyroidism and moderately differentiated adenocarcinoma lung. After completion of $16^{\text {th }}$ cycle of maintenance chemotherapy (Gemcitabine), he was readmitted with complains of fever, restlessness, cough, weakness, anemia, hypertension (180/90) and derranged kidney function. Next day he was referred to nephrology centre for further management. Before admission he was anemic, dyspnoeic, anuric, derranged renal function and was presenting with non-productive cough. On admission investigations revealed $100^{\circ} \mathrm{F}$ temperature, $86 \%$ $\mathrm{S} \mathrm{PO}_{2}, 180 / 90 \mathrm{BP}, 42 / \mathrm{min} \mathrm{RR}, 140 / \mathrm{min} \mathrm{PR}, \mathrm{S}$. urea $115 \mathrm{mg} / \mathrm{dL}, \mathrm{S}$. creatinine $4.43 \mathrm{mg} / \mathrm{dL}$, S. Sodium $120 \mathrm{mmol} / \mathrm{l}$, S. Potassium $41 \mathrm{mmol} / \mathrm{l}$. Urinalysis was not specific. Dysmorphic Red blood corpuscles were absent.

Chest examination revealed bilateral fine crepts and ronchi hence BIPAP support was given. Intravenous nitroglycerine started to control hypertension and antidiabitics, diuretics were added along with the conservative treatment of AKI. Various differential diagnosis in this setting was ruled out by appropriate investigations e.g. tumour lysis syndrome, contrast nephropathy, thrombotic thrombocytopenic purpura, obstructive uropathy and pre renal factors.

$\mathrm{X}$-ray (Figure 1) showed bilateral non-homogeneous opacity in lower zones. We requested for Bronchoscopy (Figure 2) on urgent basis and investigations were sent immediately to the lab. After stabilization Bronchoscopy was done and it revealed frothy, blood tinged, mucopurulent lavage. Bronchoscopist abandoned the procedure due to the seriousness of patient as $\mathrm{SPO}_{2}$ was going down. Microscopy of Broncho alveolar lavage (BAL) revealed occasional gram positive

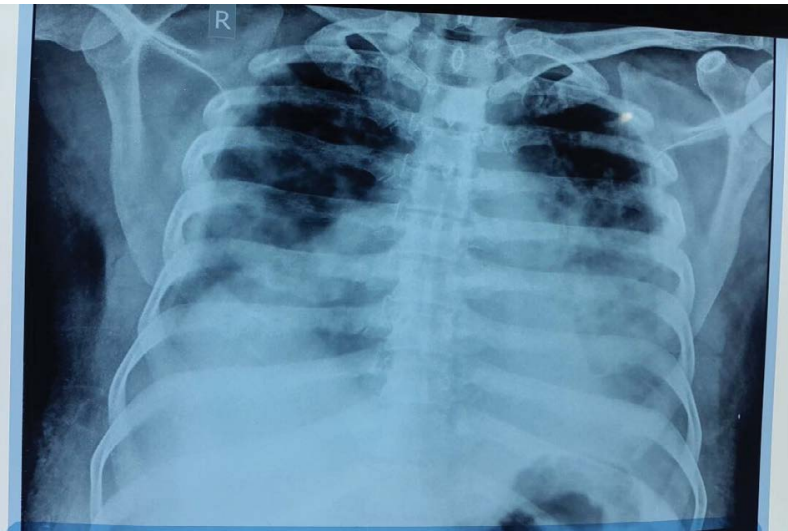

Figure 1: X-ray showed bilateral non-homogeneous opacity in lower zones.

cocci, conidia and hyphae like structures on gram staining. Lacto phenol cotton blue film confirmed the presence of fungal elements and acid fast bacilli were negative. On second day he had cough with streaky haemoptysis. Mantoux was negative. Urine and preliminary blood culture were sterile after 48 hours of incubation at $37^{\circ} \mathrm{C}$. After third day sabourad dextrose agar showed tiny grayish green colonies of Penicillium chrysogenum (Figure 3). On fifth day $\mathrm{Hb}$ was 7.5, Total Leukocyte Count (TLC) 13100 cells/cumm, with $88 \%$ neutrophils $12 \%$ lymphocytes, RBS 112, S. urea $104 \mathrm{mg} / \mathrm{dL}$, S. creatinine $5.12 \mathrm{mg} / \mathrm{dL}, 2 \mathrm{D}$ Echo showed LV 55\%, and kidneys were normal sized.

Patient was started with $5 \mathrm{mg} / \mathrm{kg}$ Liposomal amphotericin-B along with $100 \mathrm{mg}$ itraconazole twice a day for 20 days and supportive conservative treatment was given to manage AKI. Patient did not show any improvement during conservative therapy. His renal function was

*Corresponding author: Upma Narain, 62, Jawahar Lal Nehru Road, Allahabad, Uttar Pradesh, 211002, India, Tel : +919415253337; E-mail: upmanarain@gmail. com

Received: March 08, 2016; Accepted: March 22, 2016; Published: March 29 2016

Citation: Narain U, Gupta A (2016) Penicillosis in Patient of Acute Kidney Injury with Adenocarcinoma Lung: A Rare Presentation. J Nephrol Ther 6: 241. doi:10.4172/2161-0959.1000241

Copyright: ( 2016 Narain U, et al. This is an open-access article distributed under the terms of the Creative Commons Attribution License, which permits unrestricted use, distribution, and reproduction in any medium, provided the original author and source are credited. 


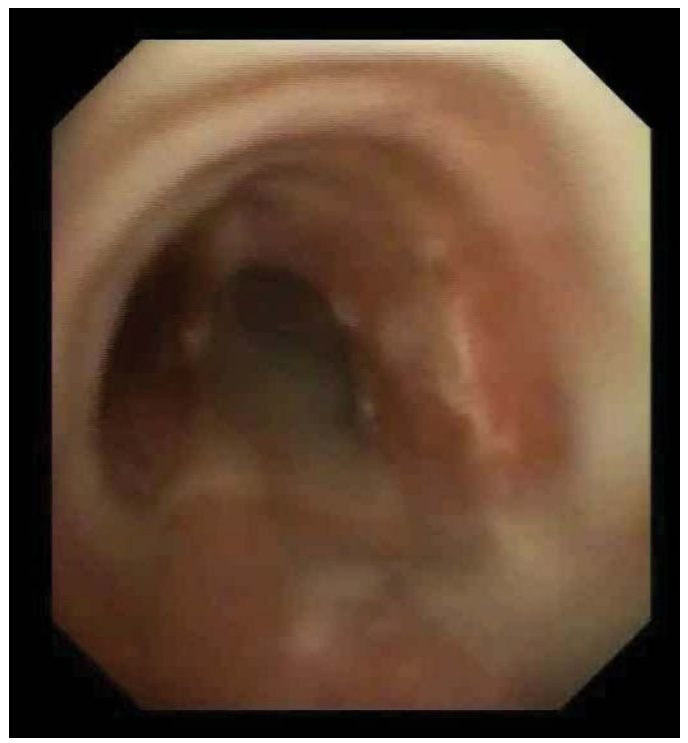

Figure 2: Bronchoscopic view.

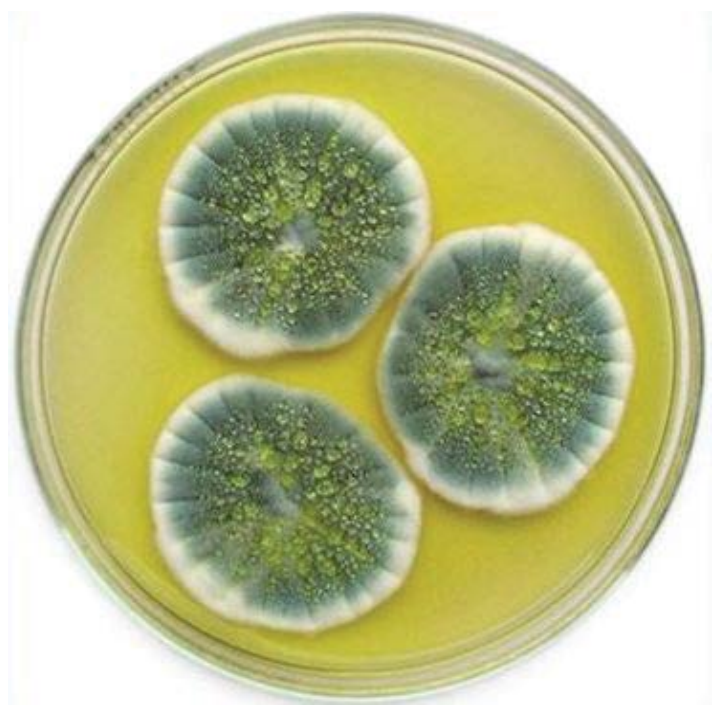

Figure 3: Macroscopic picture of Penicillium crysogeniam.

deteriorated and patient developed metabolic acidosis. Hence, he was put on haemodialysis for the indication of anuria. During dialysis five packs of packed red blood cells, three units of $100 \mathrm{ml}$ fresh frozen plasma and albumin were infused. Patient went into diuretic phase and most of the symptoms were resolved. After seven days of treatment, Hb was 10.4, 6100 cells/cumm TLC, $75 \%$ Neutophils, $25 \%$ lymphocytes $25.0,80 \mathrm{mg} / \mathrm{dl} \mathrm{S}$. urea and creatnine $3.0 \mathrm{mg} / \mathrm{dl}$. Kidney biopsy was done later on to get the exact histology against various differential diagnosis in cancer patient. According to biopsy tubules showed patchy areas of acute tubular necrosis, RBCs and WBC casts were seen in some tubules. Tubular atrophy comprised about $15-20 \%$ of cortex. Interstitium showed mild edema. Mild diffuse interstitial inflammation were seen comprising chiefly of eosinophils, few lymphocytes and plasma cells. Arteries and arterioles did not show any significant diagnostic abnormality. Direct Immunoflurosence showed 3-4 glomeruli which
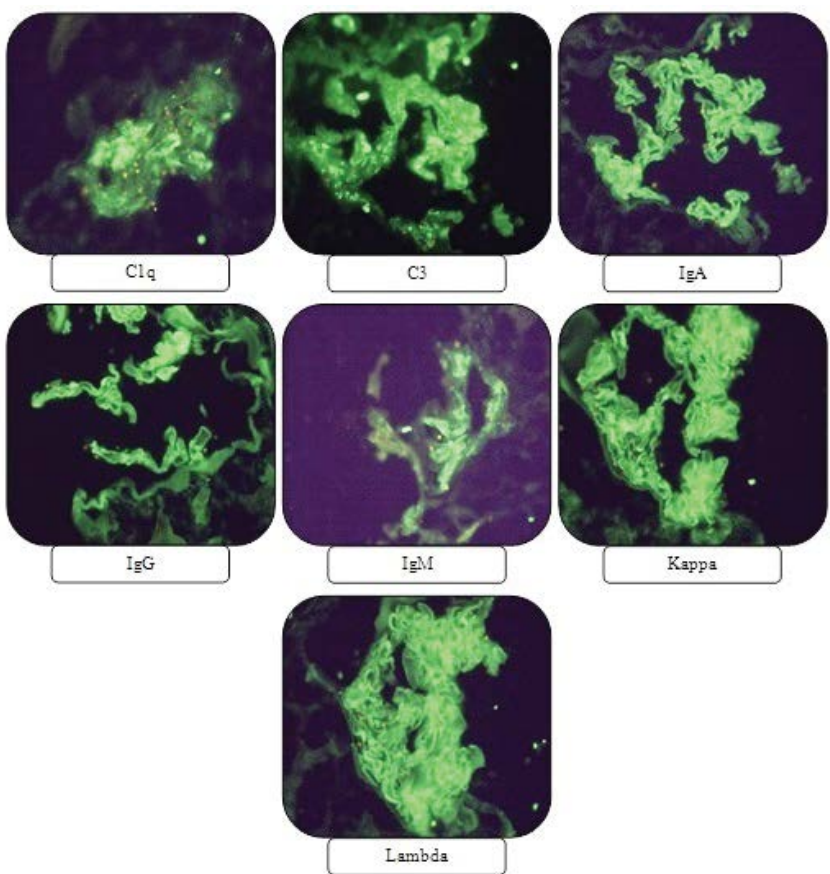

Figure 4: Direct Immunoflurosence slides of renal biopsy.

did not show staining for IgG, IgA, IgM, C3, C1q, Kappa and Lambda. Nonspecific trap noted for $\mathrm{C} 3, \mathrm{C} 1 \mathrm{q}$ and focally for IgM. Therefore findings favour to Acute Tubular Necrosis (Figure 4).

\section{Discussion}

Alterations of the immune system in uremics constitute a complex issue. On one hand, hypercytokinemia is a typical feature of uremia, likely due to accumulation of pro-inflammatory cytokines as a consequence of decreased renal elimination and/or increased generation following induction by uremic toxins, oxidative stress, volume overload, comorbidities, etc. [5,6]. On the other hand, uremia is associated with immunosuppresion due to the impact of the uremic milieu and a variety of associated disorders exerted on immunocompetent cells. Hence uremia is associated with a state of immune dysfunction characterized by immunodepression that likely contributes to the high prevalence of infections [7]. The genus Penicillium is ubiquitous, generally saprophytic, and distributed worldwide [8]. However, some species are known for their positive or negative effects on humans. The positive impacts include their use in food fermentation and the production of drugs, and the negative effects are related to the production of Mycotoxins, the induction of hypersensitivity reactions (e.g. asthama and extrinsic allergic alveolitis) and infection of the humans [9]. Members of the genus Penicillium rarely cause infections and are primarily limited to strains of the species Penicillium marnaffei [10]. As reviewed by Lyratzopoulos et al. [11], only fifteen cases of invasive infections caused by species other than $T$. marneffei have been linked to the Penicillium genus worldwide. More recently, other Penicillium species, such as $P$. chrysogenum, $P$. piceum and $P$. purpurogenum, were found to be associated with these infections [12]. In the past, Penicillium chrysogenum has been recognized as an invasive fungus in only three cases of human disease $[8,13]$. Apart from toxins liberated by fungi, one of the specific pathogenic factors of Penicillium chrysogenum causing invasive infection is its ability to grow at $37^{\circ} \mathrm{C}[14]$ because majority of Penicillium species grow below 
Citation: Narain U, Gupta A (2016) Penicillosis in Patient of Acute Kidney Injury with Adenocarcinoma Lung: A Rare Presentation. J Nephrol Ther 6: 241. doi:10.4172/2161-0959.1000241

$37^{\circ} \mathrm{C}$; however, exceptions include $P$. citrinum, $P$. decumbens and $P$. janthinellum. In our opinion, both the Penicillium chrysogenum ability to grow at $37^{\circ} \mathrm{C}$ and patient's uremic state contributed for the development of fungal pneumonitis in the patient of adenocarcinoma lung. Pulmonary infections with fungi, including Penicillium species, are associated with much higher mortality rates in patients with nosocomial infections or infections complicating organ failure. Patients with Penicillium species infections have been treated successfully with itraconazole, amphotericin B, or fluconazole. However, some patients with conditions caused by Penicillium species have died despite treatment with ketoconazole, amphotericin B, or itraconazole [15]. That is why we gave combined therapy of Amphoterecin B and itraconazole in our case and finally we achieved successful outcome. This is the first study where we made a striking and novel observation of Penicillosis caused by Penicillium chrysogenum on the onset of Acute Kidney Injury in a patient of ademocarcinoma lung. The noteworthy observation is we diagnosed early and attained successful outcome with recovery of kidney function.

\section{Conclusion}

It concludes that if identified, diagnosed and treated promptly with the help of X-ray, bronchoscopy, direct microscopy of the specimen and supportive appropriate therapy patient may lead to better outcome which is relatively uncommon but not impossible.

\section{Declaration}

The authors declaring that the results presented in this paper have not been published previously in whole or part, except in abstract format.

\section{References}

1. Chakrabarti A, Slavin MA (2011) Endemic fungal infections in the Asia-Pacific region. Med Mycol 49: 337-344.

2. Raper KB, Thom C (1968) Penicillium digitatum. A Manual of the Penicillia Hafner Publishing Company (Open Library).
3. Mok T, Koehler AP, Yu MY, Ellis DH, Johnson PJ, et al. (1997) Fatal Penicillium citrinum pneumonia with pericarditis in a patient with acute leukemia. $\mathrm{J}$ Clin Microbiol 35: 2654-2656.

4. Lam AQ, Humphreys BD (2012) Onco-nephrology: AKI in the cancer patient Clin J Am Soc Nephrol 7: 1692-1700.

5. Kimmel PL, Phillips TM, Simmens SJ, Peterson RA, Weihs KL, et al. (1998) Immunologic function and survival in hemodialysis patients. Kidney Int 54: 236244

6. Stenvinkel P, Ketteler M, Johnson RJ, Lindholm B, Pecoits-Filho R, et al. (2005) IL-10, IL-6, and TNF-alpha: central factors in the altered cytokine network of uremia-the good, the bad, and the ugly. Kidney Int 67: 1216-1233.

7. Kato S, Chmielewski M, Honda H, Pecoits-Filho R, Matsuo S, et al. (2008) Aspects of immune dysfunction in end-stage renal disease. Clin J Am Soc Nephrol 3: 1526-1533.

8. D'Antonio D, Violante B, Farina C, Sacco R, Angelucci D, et al. (1997) Necrotizing pneumonia caused by Penicillium chrysogenum. J Clin Microbiol 35: 3335-3337.

9. Yang SH, Dou KF, Song WJ (2010) Prevalence of diabetes among men and women in China. N Engl J Med 362: 2425-2426.

10. Tsang DN, Li PC, Tsui MS, Lau YT, Ma KF, et al. (1991) Penicillium marneffei: another pathogen to consider in patients infected with human immunodeficiency virus. Rev Infect Dis 13: 766-767.

11. Lyratzopoulos G, Ellis M, Nerringer R, Denning DW (2002) Invasive infection due to penicillium species other than P. marneffei. J Infect 45: 184-195.

12. Geltner C, Lass-Flörl C, Bonatti H, Müller L, Stelzmüller I (2013) Invasive pulmonary mycosis due to Penicillium chrysogenum: a new invasive pathogen. Transplantation 95: e21-23.

13. Houbraken J, Frisvad JC, Samson RA (2011) Taxonomy of Penicillium section Citrina. Stud Mycol 70: 53-138.

14. Pitt $\mathrm{Jl}$ (1994) The current role of Aspergillus and Penicillium in human and animal health. J Med Vet Mycol 32 Suppl 1: 17-32.

15. Oshikata C, Tsurikisawa N, Saito A, Watanabe M, Kamata Y, et al. (2013) Fata pneumonia caused by Penicillium digitatum: a case report. BMC Pulm Med 13: 16 . 